\title{
EDUCAÇÃO MATEMÁTICA E PAULO FREIRE: ENTRE VESTÍGIOS E IMBRICAÇÕES
}

\author{
ReGIS Forner \\ VANESSA OECHSLER \\ Alex Henrique Alves Honorato \\ Universidade Estadual Paulista (UNESP), Rio Claro, São Paulo, Brasil
}

RESUMO: Este trabalho tem por objetivo identificar possíveis sinergias entre o legado de Paulo Freire e algumas tendências em Educação Matemática. Para tanto, toma-se como base a dissertação de mestrado de Forner (2005), analisando os caminhos traçados pelos oito pesquisadores entrevistados na dissertação. Nessa direção, realiza-se uma busca a partir da leitura do Currículo Lattes de cada um dos oito sujeitos, focando nas teses e dissertações orientadas e defendidas a partir de 2004 (ano em que as entrevistas foram realizadas e transcritas). Como resultado deste estudo, observamos que em muitas das pesquisas consultadas, as teorias de Paulo Freire apenas as perpassam (vestígios) e em outras, como as de Modelagem Matemática, Etnomatemática e aquelas embasadas na Educação Matemática Crítica, há fortes interligações (imbricações).

Palavras-chave: Tendências em Educação Matemática. Modelagem Matemática. Educação Matemática Crítica. Etnomatemática.

1. INTRODUÇÃO

Iniciamos este texto apresentando o que nos moveu a abordar os temas desse trabalho, a saber: o legado de Paulo Freire e as relações com a Educação Matemática. É do conhecimento de grande parte dos acadêmicos, 
que o foco dos estudos de Paulo Freire foi alicerçado nos processos de alfabetização, não apresentando uma relação direta com a Educação Matemática. No entanto, destacamos que suas obras foram provocadoras de reflexões, também na área de matemática, como a ideia de alfabetização matemática, contextualização, educação matemática crítica, entre outras, que pretendemos discutir aqui. Para tanto, faremos uso de alguns trabalhos, sejam teses ou dissertações, os quais de alguma maneira tiveram inspiração no legado freireano para abordar questões relacionadas à Educação Matemática.

Inicialmente, gostaríamos de explicar a origem de nossas reflexões acerca de Paulo Freire. Os dois primeiros autores deste artigo já haviam trabalhado com as ideias de Paulo Freire em suas dissertações (FORNER, 2005; OECHSLER, 2012) e em outros textos (OECHSLER; GAERTNER, 2015). Em 2015, ao iniciarem o doutorado na Universidade Estadual Paulista Júlio de Mesquita Filho, em Rio Claro (SP), esses autores resolveram aprofundar seus estudos sobre Paulo Freire e relacionar as ideias dele com a Educação Matemática. Para isso, o primeiro autor deste artigo organizou um Grupo de Estudos, do qual participam estudantes de pós-graduação e professores da UNESP, incluindo os autores deste trabalho.

Nas discussões desse grupo, buscamos estudar as ideias principais defendidas por Paulo Freire. De acordo com Almeida (2009, p. 9), "Libertação, diálogo, conscientização e alfabetização como primeira leitura do mundo: são esses os conceitos básicos de sua pedagogia". Esses conceitos defendidos por Freire não necessariamente precisam estar atrelados apenas à educação de jovens e adultos, foco de seu estudo, mas podem ser expandidos para a educação, e por que não dizer para a Educação Matemática também?

Para isso, buscamos, neste trabalho, encontrar algumas possíveis aproximações entre o legado de Paulo Freire e algumas tendências em Educação Matemática, a partir do olhar de renomados pesquisadores em Educação Matemática, a saber: Dario Fiorentini e Eduardo Sebastiani Ferreira (UNICAMP), Geraldo Perez, Marcelo de Carvalho Borba, Ole Skovsmose e Pedro Paulo Scandiuzzi (UNESP), Célia Maria Carolino Pires (PUC-SP) e Maria do Carmo dos Santos Domite (USP), que foram os sujeitos da pesquisa de Mestrado do primeiro autor. A escolha desses nomes, na ocasião, foi por conta de eles desenvolverem pesquisas em nível de mestrado e doutorado e também por serem de fácil acesso ao pesquisador.

Sobre a questão das tendências em Educação Matemática, fazse necessário explicitar, primeiramente, o que pode ser considerado por "tendências". Miorim e Miguel (2001) apresentam uma sugestão para se reconhecer se um determinado campo de estudo pode ser considerado 
uma tendência. Os autores apresentam três indicadores: i) se o tema possui publicações individuais; ii) se o tema está em debate em discussões coletivas em diversas instâncias, podendo, por exemplo, refletir-se em publicações de livros ou anais de congressos; e iii) se existem comissões, comunidades científicas e cursos específicos sobre o tema em questão.

Especificamente na área de Educação Matemática, D’Ambrósio e Borba (2010) discorrem que, a partir de 1980, surgiram diversas tendências na área de Educação Matemática no Brasil, na tentativa de discutir e analisar o processo de ensino e aprendizagem da Matemática, sendo elas: modelagem matemática, uso de tecnologia digitais, etnomatemática, filosofia, perspectivas históricas e dimensões políticas da Educação Matemática.Vamos, neste artigo, buscar quais tendências em Educação Matemática têm alguma influência do legado de Paulo Freire.

Forner (2005), nas entrevistas que realizou com pesquisadores da área de Educação Matemática, tentou "buscar" na fala deles algumas possíveis relações da Educação Matemática com o legado de Paulo Freire. Em seu trabalho, ele observou que, na época, provavelmente haveria muito mais do que se apresenta no processo de fundamentação das tendências em Educação Matemática com relação às teorias de Paulo Freire, quando se considera os trabalhos que relacionam essas temáticas. Na dissertação conjecturou-se uma relação muito maior com a Educação Matemática no cenário internacional do que no brasileiro. Percebemos essa evidência em Forner (2005), o qual afirma que

[...] a obra de Paulo Freire é pouco utilizada nas pesquisas brasileiras em Educação Matemática, apesar de algumas mostrarem evidências de um trabalho mais implícito; o interessante, porém, foi perceber o quanto a teoria de Paulo Freire está relacionada com os estudos que versam sobre Educação Matemática. (FORNER, 2005, p. 179).

Diante dessa constatação e ainda pelo anseio por buscar mais contribuições de Paulo Freire à Educação Matemática, apresentamos o objetivo deste artigo: buscar e analisar as pesquisas, de mestrado e doutorado, realizadas pelos orientandos dos oito entrevistados de Forner (2005), de maneira a elaborar uma espécie de árvore genealógica similar ao movimento de Soares e Borba (2014). A intenção dessa árvore genealógica é delinear os caminhos percorridos por tais orientandos, de modo a verificar se houve uma maior aproximação entre as pesquisas brasileiras em Educação Matemática e alguns pressupostos de Paulo Freire. 
Neste trabalho, então, apresentaremos, primeiramente, algumas referências que apontam reflexões de Paulo Freire sobre a Educação Matemática e, sucessivamente, algumas considerações de educadores matemáticos que tomam como embasamento teórico alguns conceitos freireanos. Após isso, destacaremos algumas observações quanto à forma em que a teoria de Paulo Freire se encontra nos trabalhos analisados: se existem apenas vestígios, ou seja, quando conceitos freireanos apenas perpassam o tema da pesquisa; ou se existem imbricações, isto é, quando há fortes interligações entre conceitos freireanos e as tendências em Educação Matemática.

\section{O OLHAR DE PAULO FREIRE PARA A EDUCAÇÃo MATEMÁtICA}

Ao fazermos a leitura das obras de Paulo Freire em busca de considerações ou reflexões sobre a Educação Matemática, iremos encontrar algumas considerações, um tanto quanto, sutis. Isso se dá pela preocupação de Freire em pensar questões do letramento e da educação para jovens e adultos.

Na mesma direção, justificamos que estudos que buscam sinergias entre o legado de Paulo Freire e a Educação Matemática ainda são escassos no meio acadêmico, justamente pela ênfase na alfabetização que Freire deu em suas obras. Nesse sentido, gostaríamos de esclarecer que o estudo aqui proposto não esgota os conceitos que possuem sinergia entre o legado freireano e os estudos da Educação Matemática. O que percebemos é que há trabalhos em que as ideias de Freire aparecem nas entrelinhas e alguns desses trabalhos serão relatados aqui.

Assim, ao fazemos uma leitura um pouco mais detalhada, como no livro Paulo Freire: uma Biobibliografia (GADOTTI, 1996), encontramos apenas duas relações, estritamente articuladas, do educador com a Matemática. A primeira se refere ao período que ele foi tutelado pelo professor de Matemática Luiz Soares. Essa relação, a nosso ver, nunca foi alvo de pesquisas ou maiores estudos quanto à influência de um sobre o outro. A segunda relação é a única referência de estudos voltados ao ensino de Matemática. Trata-se de um capítulo escrito pela professora estadunidense Marilyn Frankenstein (2005)'.

Em seu artigo, Frankenstein (2005) relaciona a teoria de educação crítica de Paulo Freire ao contexto do currículo de Matemática. Essa relação estabelecida pela autora, sobre conceitos freireanos, acaba incorporando alguns elementos à Educação Matemática Crítica (SKOVSMOSE, 2001a), no que se refere aos temas geradores e sua relação com o currículo. Destacamos os encaminhamentos de Frankenstein no sentido de que 
os professores podem questionar os estudantes sobre os problemas que os preocupam no trabalho, sobre as atividades fora do trabalho que lhes interessam, sobre tópicos que eles gostariam de conhecer com mais profundidade, e assim por diante. Essas dimensões podem indicar o ponto de partida para o currículo. (FRANKENSTEIN, 2005, p. 127).

Outra referência importante é o encontro de Paulo Freire com os educadores matemáticos Ubiratan D’Ambrosio e Maria do Carmo dos Santos Domite $^{2}$. Nessa entrevista, Freire dialoga com D’Ambrosio e Domite quanto a reflexões no âmbito da Educação Matemática. O ponto nevrálgico é quando Freire apresenta algumas frustrações por não ter realizado maiores reflexões sobre o ensino de Matemática. Isso está evidenciado no trecho seguinte:

Bem, uma coisa eu acho, que se esse matemático que existe dormindo em mim tivesse despertado, de uma coisa eu estou certo, ele seria um bom professor de matemática. Mas não houve isso, não ocorreu, e eu pago hoje muito caro, porque na minha geração de brasileiras e brasileiros lá no Nordeste, quando a gente falava em matemática era um negócio para deuses ou gênios. Se fazia uma concessão para o sujeito genial que podia fazer matemática sem ser deus. E com isso, quantas inteligências críticas, quantas curiosidades, quantos indagadores, quanta capacidade abstrativa para ser concreta, perdemos. (FREIRE, 1995).

Tanto as indagações de Freire, quanto as considerações de Frankenstein (2005) fazem-nos pensar, na mesma direção de Borba e Skovsmose (2001), sobre duas questões: o poder formatador da Matemática e a ideologia da certeza. Quanto ao primeiro, refletimos como a Matemática molda a realidade e, a partir do segundo, o quanto o conhecimento matemático é visto por alguns como posição de superioridade aos demais conhecimentos, sendo inquestionável.

Considerando somente essas duas reflexões evidenciadas, poderíamos encontrar diversos caminhos de pesquisa na busca por possíveis aproximações entre o legado de Paulo Freire e a Educação Matemática. Contudo, por fugir ao escopo deste trabalho, não entraremos em maiores detalhes.

Na próxima seção, apresentaremos alguns trabalhos realizados por educadores matemáticos que, de alguma forma, creditam ao estudo das obras de Paulo Freire um dos elementos fundantes da pesquisa que realizavam ou realizam. Ainda, evidenciaremos os procedimentos metodológicos utilizados para analisarmos as relações entre o legado de Paulo Freire e algumas tendências em Educação Matemática, apontando vestígios ou imbricações. 


\section{A PESQUISA}

A partir dos objetivos propostos, buscamos na literatura em Educação Matemática um procedimento metodológico que ao mesmo tempo não fosse uma pesquisa bibliográfica, tampouco um estado da arte. Entendemos que pesquisas dessa envergadura (bibliográfica e estado da arte) exigiriam muito mais profundidade e complexidade do que ora pretendemos realizar.

Nesse processo de procura, encontramos em Soares e Borba (2014) um instrumento que correspondia aos nossos anseios. Nesse trabalho, os autores utilizam uma analogia ao conceito de árvore genealógica, a qual é entendida por eles como um instrumento para analisar desdobramentos de pesquisas. Nessa árvore genealógica, os autores delimitam os caminhos da pesquisa em Modelagem Matemática dos pesquisadores que foram ou ainda são membros do GPIMEM ${ }^{3}$, de modo a analisar a continuidade ou não de temas das pesquisas desenvolvidas nos trabalhos de mestrado ou doutorado no Programa de Pós-Graduação em Educação Matemática da UNESP de Rio Claro-SP.

Nessa direção, a partir dessa ideia da árvore genealógica, queremos analisar os desdobraremos de pesquisas que utilizam ideias de Paulo Freire na Educação Matemática. Delimitamos nosso estudo a partir do ano de 2004, ano em que ocorreram as entrevistas para a pesquisa de mestrado de Forner (2005). Consideramos como estágios iniciais da árvore os professores entrevistados na pesquisa de mestrado de Forner (2005): Célia Maria Carolino Pires, Dario Fiorentini, Eduardo Sebastiani Ferreira, Geraldo Perez, Marcelo de Carvalho Borba, Maria do Carmo dos Santos Domite, Ole Skovsmose e Pedro Paulo Scandiuzzi.

Com base em uma busca na Plataforma Lattes ${ }^{4}$ pelo currículo de cada um dos entrevistados, foi possível mapear os trabalhos por eles produzidos e/ou orientados que utilizaram ideias de Freire e, assim, expandir a árvore genealógica. Novas expansões podem ser realizadas, caso se faça o mesmo procedimento (pesquisa no currículo lattes) focando nesses orientandos, o que não será realizado neste trabalho, mas que pode ser realizado futuramente.

No processo de consulta à Plataforma Lattes, não encontramos nenhum trabalho do Prof. Dr. Geraldo Perez após o ano de $2003^{5}$. Quanto ao professor Eduardo Sebastiani Ferreira não encontramos também nenhum trabalho de doutorado ou mestrado que referenciasse alguma obra de Paulo Freire.

Ao nos debruçarmos sobre os trabalhos da professora Célia Maria Carolino Pires, encontramos quatro trabalhos (BERANGER, 2007; BUENO, 2013; SALMAZO, 2005; SILVA, M., 2009) que referenciaram Paulo Freire. Os 
trabalhos, em sua maioria, tratam sobre as relações entre a profissão docente e o currículo de matemática.

Das orientações realizadas pelo professor Dario Fiorentini, encontramos oito trabalhos (CASTRO, 2004; COSTA, 2004; CRISTÓVÃO, 2007; FREITAS, M., 2006; GOMES, A., 2012; GOMES, E., 2014; MEGID, 2009; MELO, 2013) que de alguma forma utilizaram alguns conceitos freireanos. $O$ trabalho do professor trata sobre a formação docente e está relacionado às interações a partir de grupos colaborativos ou comunidades de prática.

Quando nos atemos aos trabalhos orientados pelo professor Pedro Paulo Scandiuzzi, encontramos oito (CALORE, 2006; CUNHA, 2010; FONSECA, 2007; GODINHO, 2011; JESUS, 2007, 2011; MAUSO, 2006; RODRIGUES, 2006) que discutem conceitos freireanos. Os temas que envolvem as diferentes pesquisas enquadram-se na tendência Etnomatemática.

Dos trabalhos orientados pelo professor Ole Skovsmose ${ }^{6}$ no Brasil, destacam-se dois (MILANI, 2015; SOUZA, R. M., 2015). Não nos ateremos a sua produção internacional enquanto era pesquisador na Dinamarca.

Ao inventariarmos as orientações da professora Maria do Carmo dos Santos Domite, encontramos dezessete trabalhos (ANDRADE, A., 2007; ANDRADE, S., 2008; BEZERRA, 2009; CONRADO, 2005; DOMINGUES, 2006; FERREIRA, 2005; FONTES, 2010; FREITAS, R., 2009; POLICASTRO, 2010; SANTANA, 2010; SANTOS, B., 2007; SILVA, K., 2012; SILVA, V., 2014; 2008; SOUZA, R. L., 2007; 2014; VALLE, 2015) que referenciam obras de Paulo Freire. Os temas de interesse da professora convergem para aqueles do campo da Etnomatemática.

Das orientações realizadas pelo professor Marcelo de Carvalho Borba, evidenciamos quatro trabalhos (BARBOSA, 2009; MALHEIROS, 2008; SANTOS, S., 2013; SOUTO, 2013). Seus trabalhos envolvem discussões quanto a Tecnologias Digitais e Modelagem Matemática.

Apresentados os trabalhos que encontramos em nossa busca na Plataforma Lattes, iremos nos deter, na próxima seção, em delimitar o que entendemos por vestígios e imbricações nos trabalhos elencados anteriormente.

\section{Os VESTÍGIOS E AS IMBRICAÇÕES}

Depois do levantamento feito a partir das leituras das referências bibliográficas, passamos a analisar as citações de obras de Paulo Freire encontradas nos trabalhos mencionados na seção anterior.

Essa leitura dirigiu nosso olhar no sentido de que, em algumas pesquisas, a utilização de algum conceito freireano se restringe apenas a uma 
ou poucas citações que objetivam referendar a postura de um professor, sendo que poderia ser utilizado outro referencial e Paulo Freire poderia ser apenas um "adereço". A isso chamamos de vestígio porque apenas perpassa o trabalho.

Em movimento similar, quando percebemos que em alguns trabalhos, os conceitos freireanos estavam explícitos, ou seja, com muitas relações, verificando grandes interligações no trabalho analisado com o legado de Paulo Freire, a isso classificamos como imbricações.

Nessa direção, apresentamos alguns excertos dos trabalhos citados como forma de direcionar os olhares quanto ao que entendemos como vestígio ou imbricação.

S. Andrade (2008) investigou a relação da prática de pesquisa e a prática de sala de aula, buscando responder algumas perguntas como:

Qual o impacto da pesquisa em Educação Matemática na sala de aula? Como as pesquisas e os pesquisadores vêm se relacionando com a sala de aula de Matemática? [...] Como as pesquisas e os pesquisadores podem contribuir, de um modo mais efetivo, com a mudança, a transformação e a reinvenção da sala de aula de Matemática? (ANDRADE, S., 2008, p. 12).

Para isso, o autor investigou discursos de 71 pesquisadores em Educação Matemática, do Brasil e do exterior. Ao analisar esses discursos, algumas vezes, o autor remete as ideias dos entrevistados a algumas ideias de Paulo Freire. Por exemplo, ao citar o entrevistado P22, S. Andrade (2008) aponta que parece haver pesquisadores que não tem

nenhum interesse em refletir com o grupo pesquisado sobre os dados coletados na pesquisa, possibilitando assim que ambos - pesquisador e pesquisado - possam, num processo de ação-reflexão, sair - no sentido de Paulo Freire - de forma crítica do imediatamente vivido, superando assim possíveis "situações-limite do imediatamente vivido". (ANDRADE, S., 2008, p. 114).

Percebemos que o autor cita a ideia de Paulo Freire de ação-reflexão, vista em livros como Educação e Mudança, mas nem menciona tais livros neste trecho e muito menos explica a ideia de Paulo Freire sobre esses termos, tomando como natural que o leitor saiba sobre o que está sendo discorrido.

Melo (2013) analisou, em teses e dissertações, as práticas formativas desenvolvidas na disciplina de Estágio Supervisionado do curso de Licenciatura em Matemática, com o objetivo de responder à questão diretriz da pesquisa

Como o Estágio Curricular Supervisionado na Licenciatura em Matemática vem sendo concebido e descrito nas pesquisas brasileiras (2001-2010), 
que práticas formativas são desenvolvidas e investigadas e, que relações e parcerias entre sujeitos e instituições são estabelecidas nesse processo? (MELO, 2013, p. 21).

A autora recorre a Freire apenas para iniciar suas reflexões sobre o papel do educador. Para Melo (2013, p. 81), Paulo Freire "expressou com clareza os papéis de educador e educando, em um movimento de cumplicidade do ensinar-aprender e aprender-ensinar". Durante o transcorrer da tese, Melo (2013) utiliza Freire apenas para elucidar suas considerações quanto ao termo "reflexão".

Classificamos os trabalhos de S. Andrade (2008) e Melo (2013) como vestígios das ideias freireanas, por tratarem-nas de forma superficial. Já nos próximos trabalhos que exporemos, será perceptível a imbricação das ideias de Freire com o desenvolvimento das pesquisas e das reflexões.

Jesus (2007) explora uma comunidade kalunga e busca

observar a produção de conhecimento surgida da necessidade que a comunidade tem de se estabelecer de modo independente e, nessa dinâmica de produção de conhecimento, verificar o processo de difusão dessa cultura, estudar os hábitos alimentares, vestuários, dança, pinturas, artesanatos, rituais religiosos, etc. fazendo emergir as matemáticas produzidas e, ainda, descrever o processo educacional da criança Kalunga que habita o Riachão (JESUS, 2007, p. v, grifo do autor)

Para tanto, a autora se baseia na Etnomatemática que, segundo ela, tem bases filosóficas fincadas na teoria de Freire e de Lakatos, o que demonstra uma forte ligação do seu trabalho com o legado de Freire. A partir de suas observações, a autora começa a apontar diversos conceitos da teoria de Paulo Freire, mostrando que o autor está presente em todos os momentos da reflexão do trabalho, como na questão da expressão da palavra (JESUS, 2007), refletida a partir da Pedagogia do Oprimido de Freire, e o respeito à autonomia do outro, fundamentada na Pedagogia da Autonomia de Freire. Dessa forma, nesse trabalho percebemos uma imbricação muito forte da teoria de Freire nas reflexões etnomatemáticas de Jesus (2007).

Beranger (2007) busca compreender comportamentos profissionais dos professores de Matemática e como a identidade profissional deles é moldada por diversos componentes externos. O autor usa Paulo Freire como um dos referenciais teóricos do seu trabalho, buscando, em suas obras, noções sobre a educação, conscientização e diálogo. Ao final do texto, nas suas considerações sobre os dados encontrados na pesquisa, Beranger (2007) 
retoma as ideias de Freire, apontando como elas podem inspirar os professores acerca de suas práticas.

Esses resultados indicam a necessidade de ajudar os professores a debater as influências decorrentes de mudanças sociais sobre a função docente (falta de apoio aos docentes, as críticas e a demissão da responsabilidade da sociedade em face da realidade educativa), mas também seu papel como educadores, retomando as lições de Paulo Freire e outros educadores brasileiros. (BERANGER, 2007, p.100).

B. Santos (2007) discorre, em sua tese, algumas reflexões quanto às contribuições de Paulo Freire e Ubiratan D'Ambrósio para a formação do professor de Matemática no Brasil. Para o autor, Freire contribui para a formação de um professor crítico/libertador que tem papel importante na formação de um educando que seja capaz de se transformar e transformar o mundo que o rodeia, sendo a matemática uma ferramenta a qual contribui para esse processo de construção do cidadão. Pelas considerações apresentadas durante o trabalho, o autor credita a leitura das obras de Paulo Freire como uma parte indispensável para o processo de formação do professor de matemática.

Malheiros (2008), com a finalidade de investigar como ocorre a elaboração de projetos de Modelagem Matemática em um ambiente virtual de aprendizagem, inferiu a importância do diálogo, da interação, da colaboração, a negociação, o interesse, o trabalho em grupo, como elementos significativos ao elaborar os projetos alusivos a essa tendência em Educação Matemática. A autora considera que o legado freireano, além de colaborar na reflexão sobre esses elementos constitutivos dos projetos de Modelagem, também contribui para a gênese da Modelagem Matemática no cenário brasileiro.

A partir dessa classificação, apresentamos no Quadro 1 os trabalhos divididos nessas duas categorias: vestígios e imbricações. 
FORNER, R.; OECHSLER, V.; HONORATO, A. H. A.

Quadro 1: Árvore genealógica com a classificação dos trabalhos dos pesquisadores a partir da utilização de conceitos freireanos

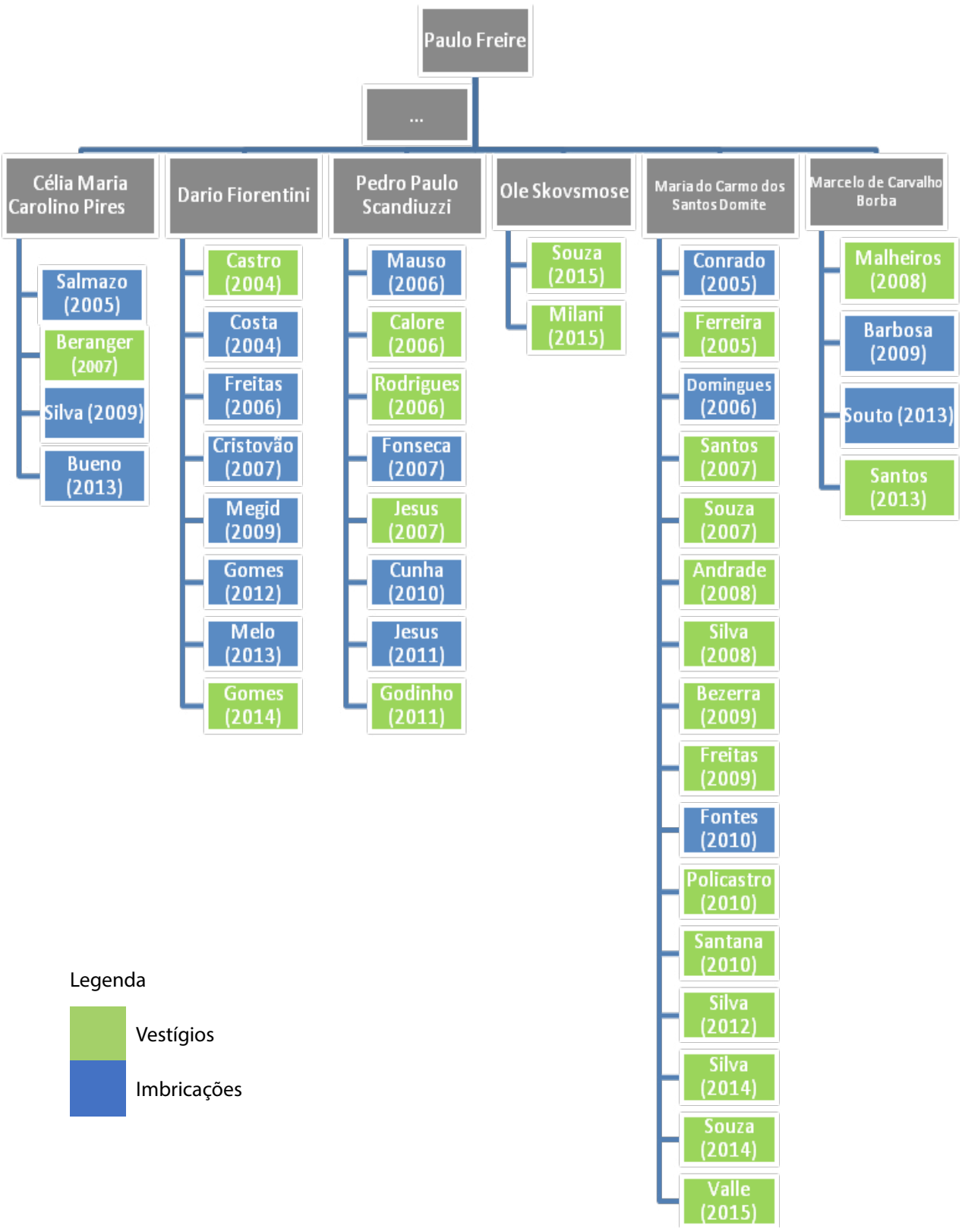

Fonte: Dos autores (2017). 
Ao propormos essa classificação, não pretendemos julgar as formas de utilização ou não de conceitos freireanos, mas apresentar que é possível verificar aproximações entre o legado de Paulo Freire e as tendências em Educação Matemática. Acreditamos, inclusive, que analisar as justificativas da não utilização ainda merece uma pesquisa muito mais detalhada, se isso for possível.

O que se percebe nesse movimento de análise das pesquisas orientadas pelos entrevistados em Forner (2005) é que a aproximação com as ideias de Paulo Freire ocorre nos trabalhos que têm por temática principal as seguintes tendências em Educação Matemática: Etnomatemática, Educação Matemática Crítica e Modelagem Matemática.

Para D’Ambrósio (2002), a Etnomatemática é fruto das experiências matemáticas realizadas por grupos culturais, de certa forma, marginalizados ou excluídos. Além de ter um caráter antropológico, ela funda-se em valores políticos ao colocar em evidência barreiras discriminatórias impostas pela sociedade dominante, expressa inclusive nas escolas.

A Educação Matemática Crítica surgiu na década de 1980, com a preocupação de estudar os aspectos políticos da educação matemática. “O axioma básico na EC [Educação Crítica] é que a educação não deve servir como reprodução passiva de relações sociais existentes e de relações de poder"(SKOVSMOSE, 2001b, p. 32). Para tanto, na Educação Matemática Crítica preconiza-se o diálogo e o uso da matemática para ler o mundo que cerca o indivíduo, podendo, a partir de reflexões, modificar a sociedade à sua volta.

Para Malheiros (2012), a Modelagem Matemática "pode ser compreendida como um caminho para o'fazer'Matemática em sala de aula" (MALHEIROS, 2012, p. 5). Segundo a autora, as atividades de Modelagem Matemática partem do contexto dos alunos, de temas de interesse deles, e por meio de interações e questionamentos, utilizando também de recursos próprios da matemática, elas são capazes de modificar as ações em sala de aula e a forma como estudantes compreendem o mundo, ou parafraseando Freire, colaborando com a sua leitura de mundo.

Com a descrição sucinta dessas três tendências, observamos a proximidade delas com diversos conceitos explorados por Freire em sua trajetória, como diálogo, criticidade, leitura de mundo, autonomia, pedagogia bancária, dentre outros. Podemos observar uma linha tênue entre a Educação Matemática Crítica, a Etnomatemática e a Modelagem Matemática, e o legado de Paulo Freire. Tal fato demonstra que, mesmo que Freire não tenha pensado na matemática ao desenvolver seu legado, diversos elementos seus têm uma relação direta no desenvolvimento da Matemática. 


\section{Algumas possíveIS DIREÇÕES}

De todo esse movimento em buscar aproximações entre o legado de Paulo Freire e das tendências em Educação Matemática, acreditamos que seja importante apontar as seguintes considerações.

Nossa intenção foi apresentar algumas aproximações entre o legado de Paulo Freire e algumas tendências em Educação Matemática e consideramos que existe uma linha muito tênue entre a Educação Matemática Crítica, a Etnomatemática e a Modelagem Matemática, e o legado de Paulo Freire. Acreditamos que ainda há muito a ser pesquisado acerca dessas considerações, pois o fizemos de forma muito superficial, carecendo de maiores aprofundamentos como forma de colaborar com as discussões realizadas no âmbito dessas tendências elencadas. Por isso, buscamos, com este artigo, promover um diálogo com os interessados nos estudos de Paulo Freire, no intuito de aprimorar pesquisas sobre os diversos temas abordados.

Também há de se destacar a influência dos estudos de Paulo Freire quanto à gênese da Modelagem Matemática no Brasil apontada por Borba e Villarreal (2005). Nesse sentido, percebemos que há avanços nas considerações em Forner (2005), mostrando que há muito mais convergência entre a Modelagem e as teorias de Paulo Freire, do que aparentemente parece.

Diante dessas evidências, procuraremos realizar novas pesquisas com o intuito de explorar novas conexões entre o trabalho de Paulo Freire e a Educação Matemática, especificamente com relação à Modelagem Matemática, foco de estudo da tese do primeiro autor e da dissertação do terceiro autor deste trabalho, de maneira a instigar os educadores a buscar em Paulo Freire fundamentos para suas práticas pedagógicas e para suas pesquisas.

Esperamos ter colaborado no sentido de pensar o quanto os estudos de Paulo Freire contribuíram e ainda podem contribuir com a Educação Matemática. Sabemos que ainda existe um caminho longo a ser trilhado nesse sentido e que carece de estudos mais aprofundados. 
MATHEMATICS EDUCATION AND PAULO FREIRE: BETWEEN TRACES AND IMBRICATIONS

AвSTRACT: This work aims to identify possible synergies between the legacy of Paulo Freire and some trends in Mathematics Education. It is based on the Forner's dissertation (2005), analyzing the paths traced by the eight researchers interviewed in the dissertation. For this, it was carried out a search from reading the Curriculum Lattes of each of the eight subjects, focusing on thesis and dissertations oriented and defended from 2004 (the year in which the interviews were conducted and transcribed). As a result of this study, it is observed that in many researches Paulo Freire's theories only pervade (traces) these works and in others, such as Mathematical Modeling, Ethnomatematics and those grounded in Critical Mathematics Education, there are strong interconnections (imbrications).

KeYwords: Trends in Mathematics Education. Mathematical Modeling. Critical Mathematics Education. Ethnomathematics.

\section{EDUCACIÓN MATEMÁTICA Y PAULO FREIRE: ENTRE RASTROS E IMBRICACIONES}

RESUMEN: Este trabajo tiene el objetivo de identificar las posibles sinergias entre el legado de Paulo Freire y algunas tendencias en la Educación Matemática. Para ello, tomamos como base la tesis de maestría de Forner (2005), que analiza los caminos trazados por los ocho investigadores entrevistados en la tesis. Con ese objetivo, se desarrolla una búsqueda a partir de la lectura del Currículum Lattes de cada uno de los ocho sujetos investigados. Esa búsqueda se centra en las tesis de maestría y doctorado orientadas y defendidas desde 2004 (año en que las entrevistas fueron realizadas y transcriptas). Como resultado de este estudio, observamos que en muchas de las investigaciones consultadas, las teorías de Paulo Freire pasan superficialmente (vestigios) y en otras, como la Modelación Matemática, Etnomatemática y en aquellas basadas en la Educación Matemática Crítica, existen fuertes interconexiones (imbricaciones).

Palabras clave: Tendencias en la educación matemática. Modelación Matemática. Educación Matemática Crítica. Etnomatemática.

\section{NotAs}

1 Esse livro, editado pela Editora Moraes, em 1987, teve outra edição realizada pela Editora Centauro em 2005.

2 Esse encontro ocorreu em uma entrevista, que substituiu a palestra inicial do 8th International Congress on Mathematical Education (ICME) de Sevilha. 
3 Grupo de Pesquisa em Informática, outras Mídias e Educação Matemática, sediado na UNESP, Rio Claro-SP, cadastrado no Diretório de Grupos do CNPQ e coordenado pelo Prof. Dr. Marcelo de Carvalho Borba.

4 Plataforma Lattes - <lattes.cnpq.br>.

5 Essa evidência talvez se justifique pelos problemas de saúde e sua aposentadoria da UNESP.

60 professor Ole Skovsmose foi incorporado recentemente ao grupo de orientadores brasileiros na UNESP de Rio Claro, orientando trabalhos relacionados à Educação Matemática Crítica e, por isso, foram encontradas investigações apenas depois de 2014.

\section{REFERÊNCIAS}

ALMEIDA, F. J. de. Paulo Freire. São Paulo: Publifolha, 2009.

ANDRADE, A. M. Avaliação, Ciclo e Progressão no Ensino de Matemática: Uma consequência refletida ou uma saída aleatória? 2007. 191 f. Dissertação (Mestrado em Educação) - Universidade de São Paulo, São Paulo, 2007.

ANDRADE, S. de. A pesquisa em educação matemática, os pesquisadores e a sala de aula: um fenômeno complexo, múltiplos olhares, um tecer de fios. 2008. 461 f. Tese (Doutorado em Educação) - Universidade de São Paulo, São Paulo, 2008.

BARBOSA, S. M. Tecnologias da Informação e Comunicação, Função Composta e Regra da Cadeia. 2009. 199 f. Tese (Doutorado em Educação Matemática) - Universidade Estadual Paulista "Júlio de Mesquita Filho", Rio Claro, 2009.

BERANGER, M. Profissionalidade e identidade profissional do professor de matemática: o fenômeno do mal-estar docente e suas implicações. 2007. 110 f. Dissertação (Mestrado em Educação Matemática) - Pontifícia Universidade Católica de São Paulo, São Paulo, 2007.

BEZERRA, K. M. O professor de matemática na periferia: acertando o passo para o conhecimento primeiro do educando. 2009. 221 f. Dissertação (Mestrado em Educação) - Universidade de São Paulo, São Paulo, 2009.

BORBA, M. C.; SKOVSMOSE, O. A ideologia da Certeza em Educação Matemática. In: SKOVSMOSE, O. Educação Matemática Crítica: a questão da democracia. Campinas: Papirus, 2001.

BORBA, M. C.; VILLARREAL, M. E. Humans-With-Media and the Reorganization of Mathematical Thinking: information and communication technologies, modeling, experimentation and visualization. New York: Springer, 2005. (v. 39).

BUENO, S. O currículo de Matemática moldado e praticado por uma professora que atua na educação de jovens e adultos. 2013. 161 f. Dissertação (Mestrado em Educação Matemática) - Pontifícia Universidade Católica de São Paulo, São Paulo, 2013. 
CALORE, A. C. DE O. As "ticas" de "matema" do aluno deficiente visual: contribuições à Educação Matemática. 2006. 132 f. Tese (Doutorado em Educação Matemática) - Universidade Estadual Paulista "Júlio de Mesquita Filho", Rio Claro, 2006.

CASTRO, J. F. Um estudo sobre a própria prática em um contexto de aulas investigativas de Matemática. 2004. 202 f. Dissertação (Mestrado em Educação) - Universidade Estadual de Campinas, São Paulo, 2004.

CONRADO, A. L. A Pesquisa Brasileira em Etnomatemática: desenvolvimento, perspectivas, desafios. 2005. 158 f. Dissertação (Mestrado em Educação) - Universidade de São Paulo, São Paulo, 2005.

COSTA, G. L. M. O professor de matemática e as tecnologias de informação e comunicação: abrindo caminho para uma nova cultura profissional. 2004. $221 \mathrm{f}$. Tese (Doutorado em Educação) - Universidade Estadual de Campinas, São Paulo, 2004.

CRISTÓVÃO, E. M. Investigações matemáticas na recuperação de ciclo ll e o desafio da inclusão escolar. 2007. 177 f. Dissertação (Mestrado em Educação) - Universidade Estadual de Campinas, Campinas, 2007.

CUNHA, A. N. DA. Diferentes realidades: ticas de matema na matemática escolar. 2010. 144 f. Dissertação (Mestrado em Educação Matemática) - Universidade Estadual Paulista, Rio Claro, 2010.

D’AMBRÓSIO, U. Etnomatemática: elo entre as tradições e a modernidade. Belo Horizonte: Autêntica, 2002.

D'AMBRÓSIO, U.; BORBA, M. C. Dynamics of change of mathematics education in Brazil and a scenario of current research. ZDM Mathematics Education, Berlim, v. 42, p. 271-279, 2010.

DOMINGUES, K. C. DE M. Interpretações do papel, valor e significado da formação do professor indígena do Estado de São Paulo. 2006. 250 f. Dissertação (Mestrado em Educação) - Universidade de São Paulo, São Paulo, 2006.

FERREIRA, R. Educação Escolar Indígena e Etnomatemática: a pluralidade do encontro na tragédia pós-moderna. 2005. 245 f. Tese (Doutorado em Educação) - Universidade de São Paulo, São Paulo, 2005.

FONSECA, A. Repensando a prática em sala de aula e o ensino/aprendizagem em Matemática a partir de uma reflexão sobre os princípios da Etnomatemática. 2007. $166 \mathrm{f}$. Dissertação (Mestrado em Educação Matemática) - Universidade Estadual Paulista, Rio Claro, 2007.

FONTES, C. G. DA. O valor e o papel do cálculo mental nas séries iniciais. 2010. $220 \mathrm{f}$. Dissertação (Mestrado em Educação) - Universidade de São Paulo, São Paulo, 2010.

FORNER, R. Paulo Freire e Educação Matemática: reflexos sobre a formação do professor. 2005. 193 f. Dissertação (Mestrado em Educação) - Pontifícia Universidade Católica de Campinas, Campinas, 2005. 
FRANKENSTEIN, M. Educação matemática crítica: uma aplicação da Epistemologia de Paulo Freire. In: BICUDO, M. A. V. (Org.). Educação Matemática. 2. ed. São Paulo: Centauro, 2005.

FREIRE, Paulo. Paulo Freire: entrevista. [1995]. Entrevistador: D'AMBROSIO, Ubiratan. [S.I]: [s.n], 1995. Disponível em: <https://www.youtube.com/watch?v=08OUA7jE2UQ>. Acesso em: 22 fev. 2016.

FREITAS, R. S. A. DE. Do conhecimento (matemático) primeiro: grandezas e medidas no centro das atenções. 2009. 150 f. Dissertação (Mestrado em Educação) - Universidade de São Paulo, São Paulo, 2009.

FREITAS, M.T.M. A escrita no processo de formação contínua do professor de matemática. 2006. 300 f. Tese (Doutorado em Educação) - Universidade Estadual de Campinas, Campinas, 2006.

GADOTTI, M. (Org.). Paulo Freire: uma biobibliografia. São Paulo: Cortez Editora, 1996. GODINHO, M. DA P. R. de. As diferenças culturais dos alunos da Educação de Jovens e Adultos do ensino Médio: uma visão etnomatemática. 2011. 190 f. Dissertação (Mestrado em Educação Matemática) - Universidade Estadual Paulista "Júlio de Mesquita Filho", Rio Claro, 2011.

GOMES, A. A. M. Aprender matemática na educação de jovens e adultos: a arte de sentir e dos sentidos. 2012. 370 f. Tese (Doutorado em Educação) - Universidade Estadual de Campinas, Campinas, 2012.

GOMES, E. B. Aprendizagem Docente e Desenvolvimento Profissional de Professores de Matemática: Investigação de Experiências Colaborativas no Contexto da Amazônia Paraense. 2014. 280 f. Tese (Doutorado em Educação) - Universidade Estadual de Campinas, Campinas, 2014.

JESUS, E. A. DE. As artes e as técnicas do ser e do saber/fazer em algumas atividades no cotidiano da comunidade kalunga do Riachão. 2007. 131 f. Dissertação (Mestrado em Educação Matemática) - Universidade Estadual Paulista "Júlio de Mesquita Filho", Rio Claro, 2007.

. O lugar e o espaço na construção do ser kalunga. 2011. 220 f. Tese (Doutorado em Educação Matemática) - Universidade Estadual Paulista "Júlio de Mesquita Filho", Rio Claro, 2011.

MALHEIROS, A. P. S. Educação Matemática online: a elaboração de projetos de Modelagem. 2008. 186 f. Tese (Doutorado em Educação Matemática) - Universidade Estadual Paulista "Júlio de Mesquita Filho", Rio Claro, 2008.

. Delineando convergências entre Investigação Temática e Modelagem Matemática. In. SEMINÁRIO INTERNACIONAL DE PESQUISA EM EDUCAÇÃO MATEMÁTICA, 5., Petrópolis. Anais... Petrópolis: SBEM, 2012. 
MAUSO, A. P.T. Estudos das medidas não oficiais brasileiras na comunidade rural de Talhados (SP). 2006. 99 f. Dissertação (Mestrado em Educação Matemática) - Universidade Estadual Paulista "Júlio de Mesquita Filho", Rio Claro, 2006.

MEGID, M. A. B. A. Formação inicial de professoras que ensinam matemática mediada pela escrita e pela análise de narrativas sobre operações numéricas. 2009. 219 f. Tese (Doutorado em Educação) - Universidade Estadual de Campinas, Campinas, 2009.

MELO, M. V. As Práticas de Formação no Estágio Curricular Supervisionado na Licenciatura em Matemática: o que revelam as pesquisas acadêmicas brasileiras na década de 2001-2010. 2013. 406 f. Tese (Doutorado em Educação) - Universidade Estadual de Campinas, São Paulo, 2013.

MILANI, R. O processo de aprender a dialogar por futuros professores de matemática com seus alunos no estágio supervisionado. 2015. 241 f. Tese (Doutorado em Educação Matemática) - Universidade Estadual Paulista “Júlio de Mesquita Filho", Rio Claro, 2015.

MIORIM, M. A.; MIGUEL, A. A constituição de três campos afins de investigação: história da matemática, Educação Matemática e história \& Educação Matemática. Revista Teoria e Prática da Educação, Maringá, v. 4, n. 8, p. 35-62, 2001.

OECHSLER, V. O ensino da matemática com um enfoque crítico: formação de cidadãos. 2012. 172 f. Dissertação (Mestrado em Ensino de Ciências Naturais e Matemática) Universidade Regional de Blumenau, Blumenau, 2012.

OECHSLER, V.; GAERTNER, R. Abordagens Matemáticas no Programa Mulheres Mil: os objetivos do milênio em foco. Blumenau: Nova Letra, 2015.

POLICASTRO, M. S. Ressonância das aulas de matemática: da produção escrita ao diálogo e transformação cognitiva. 2010. 182 f. Dissertação (Mestrado em Educação) - Universidade de São Paulo, São Paulo, 2010.

RODRIGUES, T. D. Educação Inclusiva: um caminho a ser buscado pela Educação Matemática. 2006. 138 f. Dissertação (Mestrado em Educação Matemática) - Universidade Estadual Paulista "Júlio de Mesquita Filho", Rio Claro, 2006.

SALMAZO, R. Atitudes e procedimentos de alunos frente à leitura e interpretação de textos nas aulas de matemática. 2005. 122 f. Dissertação (Mestrado em Educação Matemática) - Pontifícia Universidade Católica de São Paulo, São Paulo, 2005.

SANTANA, I. DA C. Professores de Matemática na Educação de Jovens e Adultos: o pensamento geométrico no centro das atenções. 2010. 145 f. Dissertação (Mestrado em Educação) - Universidade de São Paulo, São Paulo, 2010.

SANTOS, B. P. Dos. Paulo Freire e Ubiratan D'Ambrosio: contribuições para a formação de professores de matemática no Brasil. 2007. 444 f. Tese (Doutorado em Educação) - Universidade de São Paulo, São Paulo, 2007. 
SANTOS, S. C. Um retrato de uma Licenciatura em Matemática a distância sob a ótica de seus alunos iniciantes. 2013. 208 f. Tese (Doutorado em Educação Matemática) - Universidade Estadual Paulista “Júlio de Mesquita Filho", Rio Claro, 2013.

SILVA, K. W. A. Da. A educação de jovens e adultos na formação de professores de matemática: expectativas e desafios. 2012. 231 f. Dissertação (Mestrado em Educação) - Universidade de São Paulo, São Paulo, 2012.

SILVA, M. A. Currículos de Matemática no Ensino Médio: em busca de critérios para escolha e organização de conteúdos. 2009. 235 f. Tese (Doutorado em Educação Matemática) - Pontifícia Universidade Católica de São Paulo, São Paulo, 2009.

SILVA, V. L. da. Africanidade, matemática e resistência. 2014. 299f. Tese (Doutorado em Educação) - Universidade de São Paulo, São Paulo, SP, 2014.

. A cultura negra na escola pública: uma perspectiva etnomatemática. 2008. 205 f. Dissertação (Mestrado em Educação) - Universidade de São Paulo, São Paulo, 2008. SKOVSMOSE, O. Educação Matemática Crítica: a questão da democracia. 3. ed. Campinas: Papirus, 2001a.

SKOVSMOSE, O. Educação Matemática versus Educação crítica. In: . Educação Matemática Crítica: a questão da democracia. 3. ed. Campinas: Papirus, 2001b. p. 13-36. SOARES, D. S.; BORBA, M. C. Os Caminhos da Modelagem no "Pós"-GPIMEM: desenvolvendo uma árvore genealógica. Revemat: Revista Eletrônica de Educação Matemática, Florianópolis, v. 9, Edição Temática, p. 74-99, jun. 2014.

SOUTO, D. P. L. Transformações expansivas em um curso de Educação Matemática a distância online. 2013. 279 f. Tese (Doutorado em Educação Matemática) - Universidade Estadual Paulista "Júlio de Mesquita Filho", Rio Claro, 2013.

SOUZA, R. L. L. DE. Formação continuada dos professores e professoras do município de Barueri: compreendendo para poder atuar. 2007. 244 f. Dissertação (Mestrado em Educação) - Universidade de São Paulo, São Paulo, 2007.

. DE. Formação Contínua em Matemática para professores dos anos iniciais no Brasil e em Portugal: caminhos para o desenvolvimento do conhecimento e da prática letiva. 2014. 463 f. Tese (Doutorado em Educação) - Universidade de São Paulo, São Paulo, SP, 2014.

SOUZA, R. M. J. DE. Deficiencialismo: a invenção da deficiência pela normalidade. 2015. 172 f. Tese (Doutorado em Educação Matemática) - Universidade Estadual Paulista "Júlio de Mesquita Filho", Rio Claro, 2015.

VALLE, J. C. A. DO. Insubordina-te, educação matemática! Responsabilidade e paz em Bertrand Russell. 2015. 265 f. Dissertação (Mestrado em Educação) - Universidade de São Paulo, São Paulo, 2015. 
Regis Forner: Doutorando em Educação Matemática no Programa de Pós-Graduação em Educação Matemática da UNESP de Rio Claro-SP.

E-mail: regisforner@uol.com.br

Vanessa Oechsler: Doutoranda em Educação Matemática no Programa de Pós-Graduação em Educação Matemática da UNESP de Rio Claro-SP e professora do Instituto Federal de Santa Catarina - Campus Gaspar. E-mail: vanessa.oechsler@ifsc.edu.br

Alex Henrique Alves Honorato: Mestrando em Educação Matemática no Programa de Pós-Graduação em Educação Matemática da UNESP de Rio Claro-SP.

E-mail: alex_unesp2010@hotmail.com 